\title{
Trabalho e utopia na modernidade II: o trabalho na Cidade do Sol de Tommaso Campanella
}

\author{
Suzana Guerra Albornoz ${ }^{1}$
}

Universidade de Santa Cruz do Sul

\begin{abstract}
No lastro da Utopia de Thomas More, nos séculos seguintes dos tempos modernos, outras cidades imaginárias foram descritas. No século XVII, destaca-se a Cidade do Sol, de Tommaso Campanella. A ordem social e a hierarquia, inspiradas na astrologia, devem servir para harmonia e êxito na produção coletiva, encaminhando a redução do esforço físico na organização da sobrevivência.
\end{abstract}

Palavras-chave: Campanella, Cidade do Sol, Utopia, Autoridade, Hierarquia, Astrologia.

Work and utopia in the modern times II: work at Tommaso Campanella's The city of the sun

In the way opened by Sir Thomas More with his Utopia, and in the following modern centuries, other imaginary cities were described. In the XVIIth Century, the City of the Sun by Tommaso Campanella, must be noticed. The social order and the hierarchy, inspired in astrology, serves to the harmony and success of the collective production, therefore preparing the reduction of the physical effort in the organisation of surviving.

Keywords: Campanella, City of the sun, Utopia, Authority, Hierarchy, Astrology.

Se em O Princípio Esperança, nos Esboços de um mundo melhor, entre as utopias sociais e

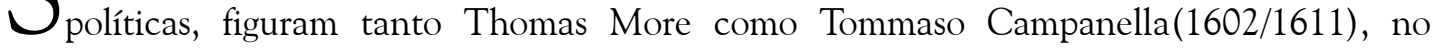
pequeno livro de Ernst Bloch sobre a Filosofia da Renascença, este toma maior lugar. Tal fato, parece-me, fala por si mesmo; entendemos que, apesar do imenso respeito que o "mago de Tübingen" votava pela força da utopia, logo, o reconhecimento dado à importância do texto de More na história das utopias, é a Campanella, na Renascença, que ele inclui entre os filósofos.

\section{Campanella na apresentação de Ernst Bloch}

O nosso filósofo hegeliano-marxista conhecido como filósofo da esperança e da utopia introduz o seu pequeno livro sobre a filosofia da Renascença acentuando que a renovação acontecida no período que entrou para a história como Renascimento ou Renascença foi uma renovação de caráter único, como nunca antes a humanidade havia conhecido. Nesta renovação, ao contrário do que comumente se apresenta, não se inclui apenas um ressurgimento das visões, valores e atitudes da Antigüidade, mas algo de inteiramente novo, segundo a interpretação de Ernst Bloch. No sentido de compreender do que se tratava na aurora da Modernidade, Bloch lembra a frase de um arquiteto que

1 Professora do Departamento de Ciências Humanas da UNISC de Santa Cruz do Sul, Rio Grande do Sul. Entre outros livros, publicou: Ética e utopia. Ensaio sobre Ernst Bloch (Movimento, 1985); O que é trabalho? (Brasiliense, 1986/2002); O enigma da esperança. Ernst Bloch e as margens da história do espirito (Vozes, 1999); O Exemplo de Antígona. Ética, educação e utopia (Movimento, 1999); Violência ou não-violência. Um estudo em torno de Ernst Bloch (Edunisc, 2000/2002). 
traduziria o sentimento de seu tempo por uma fórmula sóbria mas significativa: "O homem foi criado para agir, a utilidade é o seu destino".

Tanto os gregos como os seus descendentes romanos e cristãos tinham conservado uma atitude nítida de subvaloração da atividade e da prática em relação à contemplação e à teoria. As reflexões de Hannah Arendt, sobretudo em sua obra-prima A Condição Humana, têm explorado essas relações de valoração, para mais e para menos, para "cima" e para "baixo", em torno dessa hierarquia de valores que envolveu por tanto tempo o fazer e o pensar, a fabricação e a filosofia. O novo tempo, de afirmação da nova classe burguesa ligada à manufatura e à organização urbana, e às novas interpretações religiosas nas diversas direções da Reforma Protestante, clamava por uma nova valoração da atividade humana e isto era o novo:

\begin{abstract}
A atividade é a nova palavra de ordem. O homem novo trabalha, ele não tem mais vergonha de trabalhar. Suspende-se a proibição que a nobreza havia lançado sobre o trabalho, considerado como degradante e desonroso; assiste-se ao nascimento do homo faber que, sem ter plenamente consciência da transformação acontecida, transforma o mundo por sua atividade (Bloch, 1974, p. 6).
\end{abstract}

Esta é a grande transformação efetuada pela Renascença e, neste sentido, não se trata de um renascimento mas, antes, mais propriamente, do nascimento de algo inteiramente novo na história da humanidade. Ali, na encruzilhada da Modernidade, na despedida do tempo das catedrais e na abertura do tempo das novas ciências e técnicas, pela ponte do período das grandes navegações, nasce a civilização do trabalho, a civilização que vai afirmar o valor do trabalho, em parte de modo ideológico, de modo teórico, em parte de forma concreta - econômica, social e política.

Adivinha-se e descobre-se no indivíduo forças ignoradas até então, forças igualando aquelas que a técnica devia liberar na ordem social; a Renascença é a época da descoberta de novos meios de produção; a Musa de um Leonardo Da Vinci não negligencia estas técnicas (Bloch, 1974, p. 7).

O movimento histórico da Renascença, com o que carrega de transformação no plano das referências mítico-religiosas ou simbólico-morais e ideológico-científicas, possui sua infraestrutura no plano mais concreto dos meios de produção, do trabalho e das artes. Este processo de evolução e grande desenvolvimento das artes, que acompanha a grande transformação da visão científica e filosófica do mundo, se inicia na Itália. Consequentemente, e coerentemente, a filosofia da Renascença também se apresenta em mudança inicialmente na Itália. Assim, os filósofos Marsílio Ficino (1433-1499), Pico de la Mirandola (1463-1494), Telesio (1508-1588), Patrizzi (1529-1597) encontram-se nas origens do pensamento renascentista na Itália. É Giordano Bruno, segundo Bloch, que representa o surgimento da filosofia da Renascença propriamente dito.

Cantor do infinito cósmico, que tentou dar à sua apresentação da imanência este caráter de paixão, de interesse, de mistério, de poder, de charme, que havia marcado no mundo medieval a evocação do além (Bloch 1974, p. 24).

Descendente dos precursores filósofos italianos renascentistas, nascido, cem anos depois, próximo ao lugar de nascimento de Giordano Bruno, portanto, já em outro contexto histórico e com uma outra imagem do mundo, pode-se encontrar Tommaso Campanella (1568-1639).

2 O filósofo refere-se ao arquiteto Alberti (Bloch, 1974, p. 5). 
Embora hoje não seja muito lembrado, Campanella, personagem polêmico e contraditório, submetido a vários processos pelos órgãos de controle da ortodoxia da Igreja Católica, além de famosa contribuição de utopista expressa em sua obra Cidade do Sol, foi um pensador original. Preso por 27 anos, várias vezes torturado, a relação de Campanella com a monarquia espanhola é até hoje controversa, pois aparentemente sua teoria levava como conclusão a afirmação de uma monarquia universal de cunho religioso tal como se propunha a Espanha na época, no entanto, o motivo explícito do seu cativeiro talvez tenha sido haver conspirado contra a coroa espanhola. Menos duvidosa é a influência sofrida por Campanella do maniqueismo, provavelmente através do pensamento de Santo Agostinho e, sem sombra de dúvida, é grande a influência da astrologia apresentada por sua obra, de tal forma que se pode entender a visão de Campanella como uma espécie de cristianismo ou doutrina da Igreja calcados sobre a ciência astrológica.

Para Campanella e sua visão astrológica do mundo e da religião, o sol representa Deus, o Deus cristão do sol. A cidade é uma criação racional, hiper-ordenada, cada coisa em seu lugar. O chefe, um "Vigário do Sol" ou Metafísico. O apelido de Rei-Sol dado a Luiz XIV, da França, teria relação com o projeto de Campanella de um Estado-Sol, ultra-ordenado e hierarquizado.

A prisão de Campanella poderia ter tido outra razão de ordem filosófica. Adversário do aristotelismo, portanto, também de Santo Tomás de Aquino, Campanella, com afinidade com Giordano Bruno, defendia a idéia de que na natureza se encontra um outro livro sagrado e não pode haver contradição entre a Bíblia e o "livro sagrado da natureza" - logo, aquele que "estiver informado sobre este (o livro da natureza) estaria tão bem informado sobre a Revelação divina quanto o leitor da Bíblia” (Bloch, 1974, p. 50).

O ponto de partida do conhecimento na concepção filosófica de Campanella era a certeza do eu do indivíduo. Este não era pensado do mesmo modo que em Descartes, não significa o mesmo que o cogito, ergo sum. Para Campanella, a certeza do eu seria puramente psicológica; trata-se de uma experiência esclarecedora no plano pessoal, não esclarecendo nada no plano "objetivo", como uma demonstração matemática. Por isto, não se pode julgar Campanella precursor de Descartes, é antes mais correto compreendê-lo como um seguidor de Santo Agostinho, que introduz na filosofia a dimensão cristã da interioridade. $\mathrm{O}$ eu ponto de partida do conhecimento é, pois, para Campanella, uma experiência psíquica e pessoal, embora já se trate de um "subjetivismo de inspiração burguesa", do "eu individual que se afirma nesse tempo do início da modernidade" (Bloch, 1974, p. 51).

Poder, saber, querer, finitude, nada - tais são os pólos centrais do sistema filosófico de Tomás Campanella. O essencial que encontro em mim mesmo é finito e limitado, em suas atividades e traços fundamentais - ou seja, em seu poder, seu saber, seu querer:

O poder é a potência, o saber é a sabedoria, o querer é o amor que passou pela sabedoria (Bloch 1974, p. 52).

Poder, saber e querer, ou melhor, potência, sabedoria e amor são os traços fundamentais e as três virtudes fundamentais. A cada uma dessas virtudes corresponde um não-valor: à potência, a impotência, à sabedoria, a ignorância, ao amor, o ódio. Não apenas há oposição entre estes valores e não-valores, mas os não-valores são a demonstração da finitude de nosso poder, saber e querer humanos, logo, em nossa potência, sabedoria e amor estão misturados a sua finitude, pela impotência, a ignorância, o desamor. $\mathrm{O}$ elemento negativo, ao mesmo tempo que define, tem sua origem na limitação humana.

Na Idade Média, o elemento negativo havia sido demonizado, o nada era identificado com o mal. Na Renascença, em Campanella, a presença do nada é interpretada como elemento da finitude. O nada está lá para ser superado, vencido. De certo modo, pode-se 
dizer que "é pelo nada que aparecem - como sobre um fundo negro - a potência, a sabedoria e o amor" (Bloch, 1974, p. 54).

As faculdades básicas de poder, saber e querer, transformadas, em outro nível, nas virtudes da potência, da sabedoria, do amor, acabam sendo transpostas a um nível filosófico superior, tornando-se determinações mais sublimes e precisas destas categorias, onde se dão como "necessitas", "fatum" e "harmonia". Nestas formas de dizer as forças do ser apresenta-se o elemento da ordem, e é a ordem o princípio fundamental do pensamento de Campanella.

Tanto necessidade como fato e harmonia se opõem, embora de modos diversos e com nuances, à contingência, à "fortuna", ao azar, tudo isto que se deve ao nada. Necessidade, fato e harmonia dão contrapeso às consequências da mutabilidade, da alteridade, da provisoriedade do ser; opõem-se ao aspecto do ser que pode ser dito como non-ens ou não-ser, ao que importa dar combate, favorecendo o ser, o ens.

Campanella não inventou a expressão "livro vivo da natureza", mas desenvolveu grande esforço por descobrir e decifrar os princípios deste livro da natureza, construindo a sua teoria de como a potência, a sabedoria e o amor, por toda parte, se opõem ao nada. ${ }^{3}$

Aprender a arte de ler o livro da natureza significa tentar neutralizar o nada, a contingência, a casualidade, o azar, e isto pode ser feito lendo os níveis do real. Segundo Campanella - lembra-nos o filósofo da utopia -, o espírito-sol do mundo, reunindo em si a potência, a sabedoria e o amor, age por níveis do ser, sendo que o mundo abriga cinco níveis de perfeição: primeiro, o "mundus sitalis"; segundo, o "mundus temporalis et corporalis"; terceiro, o "mundus sempiternus"; quarto, o "mundus mentalis"; finalmente, quinto, o "mundus archetypus".

O "mundus sitalis" é a realidade da experiência onde nos encontramos, determinada e perturbada pelas contingências, realidade fortuita, provisória, passageira, imediata, imprecisa, imprevisível. O "mundus temporalis et corporalis" é o contexto e limite de nossas experiências, pelo que nos situamos na história da humanidade e no mundo concreto dos corpos. O "mundus sempiternus" é o da ordem geométrica e matemática contida no espaço. O "mundus mentalis" é o mundo lógico das categorias superiores, entidades inteligíveis que se impõem por si mesmas, enquanto evidências, embora de difícil acesso. E o "mundus archetypus", mundo supremo arquetípico, mundo dos modelos em si, inclui a totalidade das possibilidades ou os mundos possíveis em número infinito. Todos os cinco mundos ou níveis do ser correspondem a níveis ou graus de conhecimento do "livro da natureza".

Esses mundos, vistos de baixo para cima ou de cima para baixo, têm sua coesão na tendência à ordem e à unidade. $\mathrm{O}$ mundo/os mundos fogem do nada, da contingência, do azar; todas as coisas tendem para "o sol"; os mundos/ mundo é heliocêntrico; em tudo e por toda parte, em todos os níveis do ser, exerce-se a força de uma atração vertical do elemento solar.

Campanella chama este elo, heliocêntrico, de "religião". No sentido de seu pensamento, a religião não é apenas um fato que se refere aos homens, a religião tudo engloba. Se os objetos do mundo não se deixam vencer pelo nada e a dispersão, todos aspiram ao "sol", ao centro do sistema. "Religião" designa o elo que une todas as coisas e, assim, impõe-se a idéia de uma "Igreja da Natureza", regida pelo "Sol", por um ser solar, para o qual tende o "livro da natureza".

Este novo mito astral confere um sentido muito diferente, sobre o plano da teoria do conhecimento, a seu próprio ponto de partida, a saber, a auto-certeza do Eu do sujeito, fundada sobre a experiência; porque todos os homens e todas as coisas aspiram ao sol, inserem-se na ordem do sistema heliocêntrico (Bloch, 1974, p. 58).

3 Bloch, 1974, pp. 55-56.

4 Ver Bloch, 1974, p. 57. 


\title{
A Cidade do Sol ou O Estado-Sol: a utopia da ordem social
}

Estas breves linhas de introdução, pela mão do filósofo da utopia, ao todo do pensamento do polêmico monge Campanella, podem-nos ajudar a compreender o sentido do título e do conjunto de sua obra A Cidade do Sol. Podemos, com esta introdução, perceber como coerente que Campanella imagine uma vida social rigorosamente ordenada. Para ele, em cuja visão se imiscuem elementos medievais, o mundo em seu tempo vai mal, a sociedade não funciona, nada se encontra em seu lugar, há demasiada liberdade, demasiado azar, contingências, desordem, portanto, é preciso administrar e tentar pôr ordem no que está sujeito ao acaso e à imprevisão.

Bloch remete a ordem da Cidade do Sol de Campanella àquela família de ordenamentos daquele tempo em que a ordem legitimada pela teologia transita para novo tempo de desordem da liberdade pessoal: a ordem sonhada, saudade da ordem que aparece nas paisagens ao fundo dos quadros de Giotto; a ordem implacável do pecado e da virtude humanos e da misericórdia e justiça divinas, no grande poema de Dante Alighieri; a ordem perene do plano das idéias, das questões e disputas dos adversários ou discípulos de Santo Tomás de Aquino, a permanecer pelos tempos por vir:

\begin{abstract}
Pensem na magnífica ordem que preside a arte de um Giotto; cada objeto é pintado no lugar preciso onde deve estar, no lugar correspondente à sua categoria; pensem na ordem da Divina Comédia, onde cada defunto tem seu lugar preciso no inferno, no purgatório, no paraíso; pensem na ordem da escolástica, no ordenamento dos pensamentos (Bloch, 1974, p. 60).
\end{abstract}

Para Campanella, caberia à Igreja assegurar os elos entre os diferentes elementos para que se instale a ordem mais completa e geral, esta que deve englobar todas as coisas, as mais mínimas. Todavia, a astrologia se impõe, subjacente, a esta compreensão eclesial: "a ciência fundamental do Estado-Sol é, de fato, a astrologia" (Bloch, 1974, p. 60).

A inspiração astrológica de Campanella é clara e chega a extremos. O Estado-Sol manteria funcionários para prever momento e lugar mais propício para todos os atos dos cidadãos, inclusive momento e lugar para a cópula amorosa. A liberdade ficaria abolida, não poderia existir vida propriamente individual.

Em contraste com a astrologia, o mito, a superstição mesma, na Cidade do Sol aparece também uma forte tendência à racionalidade, à organização segundo a razão, que se deveria materializar num controle burocrático e estender a todo o universo.

A própria cidade é uma criação racional, elaborada sobre a planche á dessin, que contrasta com o arbitrário e o cáos das cidades medievais (Bloch, 1974, p. 61).

$\mathrm{Na}$ direção da coisa pública, Campanella concebe um "Vigário do Sol", "Sol" ou "Metafísico", soberano ao mesmo tempo imperador espiritual, pessoal e político, que governa os representantes dos três princípios fundamentais do ser, ou seja, do poder, do saber e do querer, logo, mantém sob suas ordens os três príncipes - da potência, da sabedoria e do amor.

De acordo com esta concepção, é previsto um Ministério do Poder, um Ministério da Sabedoria e um Ministério da Harmonia. O elemento da ordem se desenvolveria de modo cada vez mais total, expandindo-se como uma espécie de papado mundial. O Estado-Sol buscará a ordem extrema e a estrita forma hierárquica, onde tudo terá lugar previsto, não sendo tolerada nenhuma perturbação pela contingência ou o acaso.

O pathos da ordem exacerbada pelo sofrimento e o ódio do nada e do caos, eis o que constitui a unidade da utopia de Campanella (Bloch, 1974, p. 62). 


\section{A questão do trabalho na Cidade do Sol}

O texto Civitas Solis é apenas um anexo do terceiro livro de uma das obras filosóficas do autor, sua Philosophia realis; neste anexo, a questão do trabalho aparece no contexto de um diálogo entre o Grão Mestre e o Almirante, quando este responde àquele, que lhe pede para falar do trabalho na utópica Cidade do Sol:

Já te disse terem eles em comum a arte militar, a agricultura e a pecuária. É obrigação de todos conhecer essas artes julgadas nobilíssimas, de forma que quem exerce maior número é considerado possuidor de maior nobreza, e quem chegou a maior nobreza e a maior perfeição em algumas delas, é eleito mestre (Campanella, 1980, p. 57).

"Arte militar, agricultura e pecuária", em resumo, tal era, na realidade, o universo do trabalho ainda nos primeiros séculos da modernidade, antes da invenção da máquina a vapor, antes da hoje já adiantada aventura do mundo industrial que, por ter-se tornado mundial e abrangente, parece-nos quase como se fora perene e sempre houvesse existido.

Atividade militar, agrícola e pastoril, também ainda são estas as atividades principais, além dos trabalhos liberais e intelectuais em ligação com a manutenção da lei, políticas públicas, Estado, e os serviços modernos, estes que são os únicos em expansão em nosso tempo, ali onde e quando a indústria não pôde firmar-se, decaiu ou começa a evanescer-se.

As artes mais fatigantes obtêm maior estima, como a do artífice, a do pedreiro, etc. ninguém se recusa a exercitá-las, porque a elas se aplicam pela particular tendência revelada na infância, e também porque o trabalho é distribuído de modo que nunca possa ser nocivo à pessoa, mas, ao contrário, deve torná-la e conservá-la melhor (Campanella, 1980, p. 57).

As "artes mais fatigantes"... "como a do artífice", isto é, para além do esforço do corpo do homem no labor do campo, o autor indica aqui o trabalho da mão humana na fabricação, no plano da poiesis - distinções e conceitos gregos que nos recorda tão bem a obra de Hannah Arendt. $^{5}$

As mulheres exercem as artes menos pesadas. Todas devem ser hábeis na natação, e reservatórios especiais de água foram preparados não longe da cidade (Campanella, 1980, p. 58).

Lembramos aqui, quanto às determinações sobre as atividades das mulheres, que a inspiração parece ser antes Esparta, com suas esportistas saudáveis prontas a parir guerreiros, do que uma comunidade de irmãos e irmãs iguais diante de Deus, como no cristianismo utópico inspirado dos primeiros discípulos. Por outro lado, o planejamento exaustivo, que chega a pensar os detalhes das diferentes tarefas sociais e suas maneiras de distribuição segundo os gêneros, como fica expressa nesta afirmação, dão à Cidade do Sol uma evidente afinidade, um parentesco próximo com as utopias dos últimos séculos, tanto as imaginosas elaborações dos socialistas utópicos franceses ou ingleses do século XIX, como suas incarnações totalitárias do século XX, mesmo aquelas que se situam do lado do socialismo que se chamou de científico, e, neste sentido, apresenta traços em comum com todas as utopias planejadoras da ordem, à esquerda como à direita, quando e onde predomina a atitude de desdém e desconfiança com o inventivo e o surpreendente, com o que há de imprevisível no jogo livre das individualidades, também no comércio e no mercado, pelos quais se intromete a brecha do inesperado e do incontrolável.

5 Ver Hannah Arendt (1981), A Condição Humana. 
Já o comércio é descurado, embora conheçam o valor das moedas e fabriquem dinheiro, com o qual os embaixadores e os exploradores possam prover à subsistência nos países estrangeiros (Campanella, 1980, p. 58).

O mercado e o comércio, âmbitos da possibilidade do descontrole, portanto, da desordem, da ausência da possibilidade do controle ordeiro, neles há algo intrínseco que repugna à utopia da ordem e do controle detalhista. $\mathrm{O}$ descuido com a transação livre se soma à desconfiança ante a riqueza, o dinheiro, o capital, os bens materiais, a moeda.

À Cidade do Sol costumam chegar comerciantes das diferentes partes do mundo, que compram dos solares o supérfluo. Os habitantes não recebem dinheiro, mas trocam com as mercadorias de que precisam, sendo que, muitas vezes, também as compram com moedas. Mas, de todo o coração, riem-se os meninos solares ao verem tanta abundância de coisas deixadas por tão poucas bagatelas; não se riem, porém, os velhos. A fim de que a cidade não seja corrompida pelos maus costumes dos servos e dos estrangeiros, fazem todo o comércio nos portos, vendendo os prisioneiros de guerra ou mandando-os para fora da cidade a cavar fossas e para outros trabalhos fatigantes (Campanella, 1980, p. 58).

Os velhos são aliados da conservação e da xenofobia, como se costuma ver acontecer demasiado freqüentemente. São uma espécie de garantia e corretivo para o entusiasmo dos jovens com o movimento de intercâmbio que se traduz em riscos, em contingência, em exposição ao imprevisto, à invasão, à mudança, à desordem. E nessa utopia em que a ordem é o princípio, o fim e o critério, são os velhos os que não se deixam atingir por escrúpulos ao cuidar do comércio nos portos nem ao vender prisioneiros de guerra ou expulsá-los da cidade, encaminhando-os para trabalhos muito duros.

Para a guarda dos campos, são continuamente expedidos, juntamente com os cultivadores, quatro bandeiras de soldados, cada uma das quais sai por uma das quatro portas da cidade, que dão para o mar por estradas construídas de tijolos, de forma que as coisas e os forasteiros tenham mais fácil ingresso na cidade (Campanella, 1980, p. 58).

Embora tão valorizada a agricultura, há consciência do caráter de esforço contido no labor do campo, que por isto exigiria acompanhamento militar e motivação patriótica. Junto com os cultivadores vão os soldados.

As estradas têm este motivo produtivo e econômico, de servir ao trabalho no campo, ao ir e vir do campo e da cidade, bem como para o transporte dos produtos, portanto, para o serviço à sobrevivência da população.

Mas também são as estradas que facilitam o ingresso dos forasteiros, que assim se quer facilitar, o que à primeira vista poderia parecer contraditório, quando se viu em afirmação anterior o duro destino dado aos estrangeiros prisioneiros.

Esses [os forasteiros] são tratados com gentileza e magnificência. Vivem, por três dias, a expensas públicas. Ao primeiro encontro lavam-lhes os pés e conduzem-nos, depois, para a cidade, onde lhes dão lugar na assembléia e à mesa, assistidos e servidos por pessoas especiais. Quando desejam tornar-se cidadãos solares, são submetidos a provas, um mês no campo, outro na cidade. Se então se decidem e a admissão é concedida, efetuam-se juramentos e cerimônias (Campanella, 1980, p. 59).

Aparece aí uma relação, mais uma vez, racional, desta vez com os forasteiros, cujo acolhimento está previsto ser civilizado, regrado, não inteiramente aberto que não esteja sob nenhum controle, mas "submetido a provas", no campo como na cidade. 
Grandemente valorizada a agricultura: cada palmo de terra dá lucro. Estudados os ventos e as estrelas, saem eles, deixando poucos montando guarda à cidade, para arar, semear, escavar, sachar, ceifar, vindimar, acompanhados de trompas e tímpanos, e em brevíssimo tempo é terminado todo o trabalho, economizando, com arte, tempo e fadigas (Campanella, 1980, p. 59).

Encontra-se aqui a mesma esperança contida já na Utopia de Thomas More, de que uma melhor distribuição do trabalho leve a uma diminuição da pena da labuta para cada indivíduo. Como os habitantes vão em grande número ao trabalho do campo, além de cuidados os aspectos científicos e procurada a boa orientação técnica - o que se pode ler na expressão "estudados os ventos e as estrelas", o seu tempo de trabalho pode ser reduzido.

Estamos ainda no universo da cultura latina e católica, na qual há bem mais e melhor a fazer além de arar, semear, escavar, ceifar, esperando-se que o esforço partilhado e bem feito possibilite abreviar o tempo consagrado ao esforço produtivo.

Usam carros munidos de velas, que servem mesmo quando sopra vento contrário, graças a um admirável aparelhamento de rodas, e, quando falta o vento, é belíssimo ver como um único animal puxa um imenso e pesadíssimo carro (Campanella, 1980, p. 59).

Neste ponto, Campanella arrisca imiscuir-se no domínio da utopia técnica, aquela que se fez presente de modo tão magnífico na Nova Atlantis de Francis Bacon ${ }^{6}$. Suas sugestões neste domínio são discretas, contidas. Nada que se assemelhe ou aproxime das ousadias do seu colega inglês que, no entanto, tem hoje a confirmação do seu realismo utópico, por terem sido muitos dos seus seres técnicos imaginários concretizados em fatos adquiridos pela técnica ocidental dos últimos séculos, de modo que a Nova Atlântida pode ser considerada como a ficção científica do seu tempo, que no nosso encontrou realização.

Enquanto isso se faz, as bandeiras que guardam o território vão saindo ao redor, alternando-se freqüentemente. Não fazem uso dos adubos que estes corrompem as sementes e produzem cereais malsãos, enfraquecendo e abreviando a vida, da mesma forma que as mulheres que, sem ser belas por exercício, mas por artifício, dão à luz filhos lânguidos e raquíticos (Campanella, 1980, p. 59).

De um lado, antecipa-se uma preocupação ecológica extremamente atual, a de não diminuir a força da terra pela interferência de adubos e artifícios que diminuam a força dos alimentos. De outro, insinua-se ainda o preconceito em relação às mulheres, pensadas como destinadas para a maternidade, mesmo como responsáveis pela qualidade da progenitura, quando a beleza pelo exercício há de contribuir, mas por artifício poderá desfavorecer.

Por isso, não põem nada sobre a terra, trabalham com assiduidade, sendo que, de um livro intitulado Geórgicas, aprendem os segredos que se requerem para um pronto nascimento e uma feliz multiplicação das sementes. Trabalha-se somente a porção de terra que baste para as necessidades dos cidadãos, ficando a restante para o pasto dos animais (Campanella, 1980, pp. 59-60).

A terra é trabalhada com ciência e utilizada com parcimônia, com aquele respeito muitas vezes esquecido pela modernidade industrial imbuida da ideologia da produtividade máxima. O critério seriam "as necessidades dos cidadãos", mas também consideradas, além das necessidades humanas, as dos outros animais.

Por esses detalhes de previsão, digamos, ecológica, a utopia de Campanella suaviza o seu caráter de imposição autoritária e hierárquica da ordem, pois esta ordem adquire um sentido de busca da harmonia natural.

6 Bacon, Pensadores, 1972. 
Em grande estima é tida, igualmente, a nobre arte que se relaciona com a reprodução e a criação de bois, cavalos, ovelhas, etc. Não mandam ao pasto os garanhões juntamente com as éguas, mas, quando ocorre, emparelham-nos no átrio das estrebarias campestres, observando o Sagitário em bons aspectos com Marte e Júpiter. Para o gado bovino, observam o Taurus, para as ovelhas o Áries, etc., segundo a doutrina (Campanella, 1980, p. 60).

De acordo com o que afirmávamos na introdução e já era salientado pela apresentação de Ernst Bloch, a doutrina da astrologia dá fundamento ao todo e ao detalhe da utopia da Cidade do Sol. Assim, os detalhes do pastoreio e do manejo dos animais, nas técnicas e usos da criação de ovinos, eqüinos, bovinos, também se orientam pelos conhecimentos esotéricos da ciência dos astros.

A família dos animais domésticos encontra-se sob os Pléiades. As mulheres, com prazer, conduzem os patos e os gansos ao pasto, fora da cidade, onde há lugares em que os encerram, havendo outros onde podem preparar queijo, manteiga e toda a espécie de laticínios. Dão também alimento a um grande número de capões, etc., aperfeiçoando-se em tudo isso pela leitura de um livro intitulado Bucólica (Campanella, 1980, p. 60).

Mais uma vez se acentua aqui a distribuição de tarefas conforme ao gênero, algo que só em nosso tempo começa a ser revisto e abandonado.

Possuem de tudo com fartura, desejando cada qual mostrar-se o primeiro no trabalho, que não fatiga e é útil. Os seus ânimos são dóceis e assim obedecem a quem preside aos mesteres, chamando-lhe rei. Nem esse nome lhes desagrada, pois é criação dos habitantes solares, que não o entendem à maneira dos ignorantes (Campanella, 1980, p. 60).

Na utopia de Campanella, elaborada no século XVII, bem como nas utopias concretas dos nossos últimos séculos - XIX e XX, até o XXI, cada qual deseja "mostrar-se o primeiro no trabalho"... lugar-comum difícil de questionar ainda em nosso tempo. Interessante e original é a observação que se lhe segue, sobre o fato de, na planejada Cidade do Sol, o trabalho não fatigar e ser útil. Por este breve fim de frase, intromete-se na afirmação o testemunho da consciência de que o trabalho pode não provocar fadiga, como é facilitado hoje pelo auxílio dos engenhos técnicos cada vez mais sofisticados com que contamos; mas, por outro lado, além disso, indiretamente está dito que nem todo trabalho é útil, mesmo quando exige esforço e, portanto, provoca cansaço.

A idéia de um trabalho útil nos provoca a registrar a possibilidade da existência de trabalhos inúteis, sobre o que me parece fecundo pensar. Muito freqüentemente, parece-me, desaparece da linguagem esta lucidez, sendo o trabalho considerado quase sinônimo de atividade útil.

Ainda há a destacar, neste parágrafo, a afirmação da submissão ao rei que, na Cidade do Sol, acontece aparentemente sem dor nem desagrado. Campanella atribui aos "ignorantes" a dificuldade para obedecer "a quem preside aos menesteres". O autor indica que a cultura, a educação ou o progresso no conhecimento agem no sentido da disciplina e do gosto da obediência, como se a ignorância estivesse na origem da rebeldia e dificuldade para obedecer.

Maravilhado ficarias certamente ao ver a ordem com que aqueles homens e mulheres, indistintamente, procedem sob a obediência do rei. E assim procedem considerando-o um pai ou um irmão mais velho, sem o ressentimento que se verifica entre nós. Possuem bosques e florestas abundantes em feras e animais para o exercício da caça (Campanella, 1980, pp. 60-61). 
O fato de submeter-se ao rei possibilita a ordem perfeita, que é o fim perseguido pelo utopista filósofo Campanella. A alusão à relação dos súditos com o rei que se assemelharia à de filhos para com o "pai ou um irmão mais velho" fica bem esclarecida pelo acréscimo: "sem o ressentimento que se verifica entre nós", esclarecimento que podemos interpretar de ambos os modos: ou que entre os modernos ocidentais é comum verificar-se o ressentimento para com o governante, ou que entre nós o ressentimento é comum verificar-se para com o pai ou o irmão mais velho.

A arte náutica é muito apreciada. Possuem navios, alguns dos quais, mediante um admirável artifício, viajam sem velas e sem remos. Conhecem o curso das estrelas, o fluxo e o refluxo do mar. Navegam para adquirir novos conhecimentos sobre os povos, os países e as coisas (Campanella, 1980, p. 61).

O que hoje parece óbvio, no tempo em que se escreve a Civitas Solis é antecipação utópica, elaboração da imaginação antecipante.

Quando o filósofo pensa que "mediante admirável artifício, viajam sem velas e sem remos", é quase como se hoje disséssemos: "podem entrar no túnel do tempo e voltar como quiserem ao mundo de seus antepassados, assim como visitar o mundo futuro de seus descendentes", ou seja, refere fatos que na realidade ainda não são possíveis, embora já habitem a imaginação humana e as obras de ficção, da chamada "ficção científica". Os novos meios e as novas técnicas de transporte, que desenvolvem a ciência, retornam à sua origem, alimentando o novo desenvolvimento técnico-científico, que leva sempre a novos meios de transporte e comunicação, de artifício cada vez mais admirável.

Não ofendem ninguém, mas também não toleram injúrias, brigando só quando agredidos. Dizem que o mundo alcançará tanta sabedoria que os homens viverão como eles. Admiram a religião cristã e esperam, neles e em nós, a confirmação da vida dos apóstolos (Campanella, 1980, p. 61).

Aqui se transcende a questão do trabalho, remetendo de volta à visão filosófica, moral e religiosa, onde a questão da violência interpela e a opção pela não-violência, pelo menos, à orientação de "brigar somente quando agredidos", se estabelece como própria da sabedoria que o mundo deve alcançar, a exemplo dos habitantes da Cidade do Sol. Embora de modo discreto, estas atitudes e virtudes - a não-violência como a sabedoria -, são referidas à religião cristã, pela qual se espera a confirmação da vida dos apóstolos.

\section{Referências}

Obras citadas

Bloch, E. (1974). La Philosophie de la Renaissance. Paris: Payot.

Campanella, T. (1980). A Cidade do Sol. Lisboa: Guimarães Editores.

Outras obras referidas ou consultadas

Arendt, H. (1981). A Condição Humana. Rio de Janeiro: Forense Universitária.

Bloch, E. (1982). Le Principe Espérance, II. Paris: Gallimard.

Bacon, F. (1973). A Nova Atlântida (Os Pensadores, Vol. XIII). São Paulo: Abril. 
Bruno, Galileu E Campanella (Os Pensadores, Vol. XII). (1973). São Paulo: Abril.

Huisman, D. (2001). Dicionário dos filósofos. São Paulo: Martins Fontes.

Endereço para correspondência: suzanaalb@viavale.com.br

Recebido em: 20/04/2004

Envio de pareceres em: 08/09/2004

Aprovado em: 08/10/2004 